\title{
Changes in body temperature of critically ill patients submitted to bed bathing: a crossover clinical trial
}

\author{
Alterações na temperatura corporal de pacientes críticos submetidos ao banho no leito: ensaio clínico crossover
}

Cambios en la temperatura corporal de pacientes críticamente enfermos sometidos a baños en cama: ensayo clínico crossover

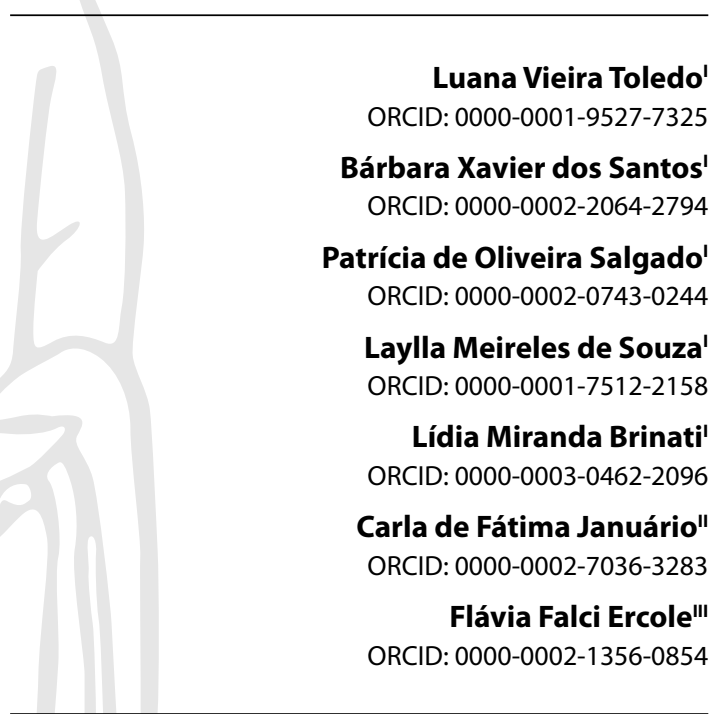

'Universidade Federal de Viçosa. Viçosa, Minas Gerais, Brazil. "Universidade Federal de Minas Gerais, Hospital das Clínicas. Belo Horizonte, Minas Gerais, Brazil. "'Universidade Federal de Minas Gerais. Belo Horizonte, Minas Gerais, Brazil.

How to cite this article: Toledo LV, Santos BX, Salgado PO, Souza LM, Brinati LM, Januário $\mathrm{CF}$, et al. Changes in body temperature of critically

ill patients submitted to bed bathing: a crossover clinical trial. Rev Bras Enferm. 2021;74(2):e20200969. https://doi.org/10.1590/0034-7167-2020-0969

\section{Corresponding author: Luana Vieira Toledo E-mail: luana.toledo@ufv.br}

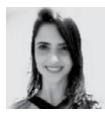

EDITOR IN CHIEF: Antonio José de Almeida Filho ASSOCIATE EDITOR: Fátima Helena Espírito Santo

\begin{abstract}
Objectives: to compare tympanic and axillary body temperature values of critical patients before and after the traditional and dry bed bath. Methods: this is a randomized, open crossover clinical trial conducted with 50 adult critical patients. All patients received both types of bed bathing. The tympanic and axillary temperature values were measured at the beginning and end of the baths. The Wilcoxon test or paired Student's t test was used. Results: elderly and male patients predominated. There was no significant difference between tympanic temperature medians measured during the traditional bed bath $(p=0.707)$ and dry bath $(p=0.101)$. Axillary temperature means reduced at the end of the baths $(p=0.001)$, being $36.12^{\circ} \mathrm{C}$ in the traditional bath and $35.92^{\circ} \mathrm{C}$ in dry bath. Conclusions: bed bath, regardless of the method used, caused a reduction in critical patients' axillary temperature.

Descriptors: Baths; Nursing; Clinical Trial; Body Temperature; Intensive Care Units.
\end{abstract}

\section{RESUMO}

Objetivos: comparar os valores de temperatura corporal timpânica e axilar dos pacientes críticos antes e depois da realização do banho no leito tradicional e a seco. Métodos: ensaio clínico randomizado crossover, aberto, realizado com 50 pacientes críticos adultos. Todos os pacientes receberam os dois tipos de banho no leito. Os valores da temperatura timpânica e axilar foram mensurados no início e fim dos banhos. Utilizou-se o Teste de Wilcoxon ou $t$ de Student pareado. Resultados: predominaram os pacientes idosos e do sexo masculino. Não houve diferença significativa entre as medianas de temperatura timpânica aferidas durante o banho no leito tradicional $(p=0,707)$ e a seco $(p=0,101)$. As médias da temperatura axilar reduziram ao final dos banhos $(p=0,001)$, sendo $36,12^{\circ} \mathrm{C}$ no banho tradicional e $35,92^{\circ} \mathrm{C}$ no banho a seco. Conclusões: o banho no leito, independentemente do método utilizado, provocou redução na temperatura axilar dos pacientes críticos.

Descritores: Banhos; Enfermagem; Ensaio Clínico; Temperatura Corporal; Unidades de Terapia Intensiva.

\section{RESUMEN}

Objetivos: comparar los valores de temperatura corporal timpánica y axilar de pacientes críticos antes y después del baño en la cama tradicional y seca. Métodos: ensayo clínico crossover, aleatorizado y abierto, realizado con 50 pacientes adultos críticos. Todos los pacientes recibieron ambos tipos de baños en la cama. Los valores de temperatura timpánica y axilar se midieron al inicio y al final de los baños. Se utilizó la prueba $t$ de Student o Wilcoxon pareada. Resultados: predominaron los pacientes ancianos y varones. No hubo diferencia significativa entre las medianas de temperatura timpánica medidas durante el baño en la cama tradicional $(p=0,707)$ y la seca $(p=0,101)$. Las medias de temperatura axilar disminuyeron al final de los baños $(p=0,001)$, siendo $36,12^{\circ} \mathrm{C}$ en el baño tradicional y $35,92^{\circ} \mathrm{C}$ en el baño seco. Conclusiones: el baño en cama, independientemente del método utilizado, provocó una reducción de la temperatura axilar de los pacientes críticos.

Descriptores: Baños; Enfermería; Ensayo Clínico; Temperatura Corporal; Unidades de Cuidados Intensivos. 


\section{INTRODUCTION}

In nursing practice, the measurement of body temperature is part of the assessment of critical patients' health status, assisting professionals in the definition of diagnoses and therapeutic actions ${ }^{(1)}$. Under physiological conditions, the average human body temperature is equivalent to $36.6^{\circ} \mathrm{C}$, being maintained by the thermoregulatory system located in the hypothalamus region ${ }^{(2)}$. Its measurement can be carried out invasively or not, using thermometers positioned in different locations of the human body ${ }^{(3)}$. Invasive methods are considered the gold standard for obtaining central body temperature; however, the disadvantages are that they are more likely to generate complications and/or infections for patients $\mathrm{s}^{(4)}$. Thus, non-invasive methods using hygienic, accessible thermometers, suitable for different health services and that express reliable values of temperature should be prioritized ${ }^{(1,5)}$.

Among the non-invasive forms, the tympanic temperature (TT), Obtained from an infrared thermometer positioned in the ear canal, is the one that presents greater accuracy and precision, possibly related to the proximity to the hypothalamus region ${ }^{(1)}$. However, in clinical practice, it is observed that, in most Intensive Care Units (ICUs), the axillary temperature values (AT) Are still used as a parameter for the definition of nursing diagnoses related to thermoregulation ${ }^{(6)}$. This measurement method has its practicality and low cost as advantages, however it has less accuracy as disadvantages ${ }^{(7)}$.

Changes in body temperature have important effects on oxygen supply and consumption. Mainly, for critically ill patients, these changes may contribute to a worse evolution of the clinical picture ${ }^{(8)}$. It is evident that low room temperatures of ICUs' climatized environments can, by themselves, cause variations in body temperature, causing instabilities and slowing the recovery process of patients ${ }^{(9)}$. Moreover, patient exposure to the environment can be even greater when performing basic body care, such as bed bath ${ }^{(10)}$. Maintaining patients' body hygiene is a routine activity in ICUs defended as a priority by Florence Nightingale ${ }^{(11)}$, a precursor of modern nursing. Despite the benefits provided by the practice of bed bath, one cannot ignore the potential risks to which patients are exposed during its performance, especially related to oximetric and hemodynamic instability ${ }^{(12)}$.

Upon receiving the traditional bed bath, patients, in addition to exposing the naked body to the environment, maintain direct contact with the bath water, which can often become cold and increase patients' body temperature ${ }^{(13)}$. In order to minimize the negative effects of this exposure, it is suggested that the bed bath of critically ill patients be carried out keeping the water temperature at or above $40^{\circ} \mathrm{C}^{(8)}$. Despite the importance of controlling bath water temperature, it appears that, in practice, this is not a routine activity in health services ${ }^{(13)}$.

In this context, dry bed bath emerges as an alternative, made with disposable compresses moistened with emollient solution ${ }^{(14)}$. This type of bath has been considered faster than the traditional bath, thus reducing patient exposure time ${ }^{(15)}$. Moreover, its execution is independent of water and, consequently, does not suffer influences from its cooling, as in the traditional bath. However, there is a lack of studies aimed at assessing the changes in body temperature of critically ill patients after these two types of bed bath have been performed, especially since dry bathing is still a recent intervention in nursing practice. Furthermore, there are no studies that explore the relationship between different methods of measuring non-invasive body temperature with bed bathing in critically ill patients.

Bed bathing and body temperature control are attributions of the nursing staff that can influence the control of metabolic activities and the comfort of patients, considered extremely important for maintaining life. Recognizing whether a routine nursing action, such as a bed bath, can cause changes in the thermal balance of critically ill patients provides subsidies for the reorientation of practice and adjustments in the way of care. Thus, there is a need to carry out studies aimed at comparing the body temperature values of critical adult patients submitted to different types of bed bath. Based on the results of studies with high methodological rigor, it will be possible to evidence whether there is a difference between the effects of these two types of bath on changes in body temperature of critically ill patients and which one has less influence on thermal balance.

\section{OBJECTIVES}

To compare tympanic and axillary body temperature values of critical patients before and after the traditional and dry bed bath.

\section{METHODS}

\section{Ethical aspects}

This study was approved by the Research Ethics Committee of the promoting institution and registered on the Brazilian Registry of Clinical Trials (ReBEC) platform: RBR-5qwkqd. The Informed Consent Form (ICF) was signed by patients or their legal representative after providing guidance on the research.

\section{Design, period, and place of study}

This is an open, randomized crossover clinical trial (RCT) performed with patients admitted to an ICU of a teaching hospital. All participants received, at random, both bathing interventions, being allocated to the control group at the time of traditional bed bathing and to the intervention group during dry bed bathing. At the beginning and at the end of each bath, TT and AT values were recorded.

As this is a crossover study, patients themselves were considered their control, extinguishing the variation between subjects. This work followed the recommendations of the Consolidated Standards Of Reporting Trials (CONSORT) $)^{(16)}$.

\section{Population; inclusion and exclusion criteria}

The study population consisted of all patients admitted to ICUs between September 2018 and February 2019, totaling 56 patients. Non-probabilistic sampling for convenience was used due to the absence of data in literature on behavior of tympanic and axillary temperatures during bed bathing for critically ill patients.

Of the total number of patients admitted to ICU, those who were 18 years of age or older and who had the nursing diagnosis "Self-Care Deficit: Bathing" were included. Patients with conditions that affected the regulation of body temperature, such as neurological changes and extensive burns, were excluded. 
Patients dying, being discharge or transfer before receiving the second bath procedure were considered as discontinuity criteria.

Thus, of the 56 hospitalized patients, two were excluded because they did not meet the inclusion criteria. Of the 54 patients recruited, four died before receiving the second bath. At the end, the sample included 50 patients.

\section{Study protocol}

Bed bath interventions were performed based on randomization performed by an independent researcher, external to the research, through the website www.randomization.com. A randomization table was created, in blocks of 10 individuals, with the permutation of control (traditional bath) and intervention (dry bath) groups. Then, the same external researcher distributed the random bath sequence to each patient in opaque, sequential, numbered and sealed envelopes. The allocation confidentiality of each patient was maintained until the moment of bathing. After ICU admission, patients received both types of bed bath (traditional and dry), with a minimum interval of 24 hours (washout) between them, in order to avoid the residual effect of one intervention on the other (carryover).

To participate in this study, eight auxiliary researchers underwent theoretical-practical training in order to guarantee the performance of standardized interventions. Training was guided by the protocol's content prepared by the main researcher, taking as a reference the bath wipes' manufacturer (feel clean) recommendations and the scientific literature ${ }^{(17)}$.

Training was carried out in two stages. In the first one, the researchers received a printed material containing the theoretical explanation of bed bath procedures and watched a video, made by the main researcher, demonstrating the steps' performance of these procedures in a simulated environment. For the second stage, the auxiliary researchers were divided into pairs, performing the practical reproduction of baths in a simulated environment. They were assessed to correctly carry out the interventions from a checklist containing the necessary steps for a proper performance of bathing, based on the protocol and validated by nursing professors at a federal public higher education institution. Researchers who reached an Agreement Index (Al) greater than or equal to 0.9 in relation to the activities performed in each of the baths were considered able to participate in the study. The agreement index was verified using the formula: $\mathrm{Al}=(\mathrm{NA} / \mathrm{NA}+\mathrm{ND}) \times 100$, where $\mathrm{NA}$ corresponds to the number of agreements, and ND, to the number of disagreements ${ }^{(18)}$. Two training cycles were carried out, so that all assistants reached the aptitude to participate in the research.

The traditional bed bath included cleaning with soap and water, rinsing and drying the body. The hygiene started in the face region, followed by the right and left upper limbs, trunk, right and left lower limbs and ending the anterior part with the genital hygiene. Patients were positioned in lateral decubitus so that it was possible to complete the hygiene of the dorsal part of the trunk and the gluteus. When patients were lateralized, bed linen was replaced, according to the protocol ${ }^{(17)}$. It is noteworthy that, during bathing, the researchers used sheets to cover the parts of patients' bodies that were not being cleaned.

For dry bed bathing, individual packs of bath wipes produced by the FW (Feel Clean ${ }^{\circ}$ ) group - wet wipes were used. The procedure was performed according to the guidelines provided by the manufacturer of tissues and the one described in the protocol ${ }^{(17)}$. The sequence of the body part to be cleaned was the same as the traditional bed bath, and the parts that were not being cleaned were kept covered sheets throughout the intervention. All two types of bed bath were performed by the main researcher and an auxiliary researcher. During the baths there was no blinding, as both the researchers and patients, when lucid and oriented, knew the type of bath they should proceed or receive.

The primary outcomes were TT, measured from a digital ear thermometer (Incoterm ${ }^{\circ} \mathrm{TH} 809$ ) and AT, measured using a digital clinical thermometer (G-TECH $\left.{ }^{\circ} \mathrm{TH} 1027\right)$. Data were collected at the beginning and at the end of each type of bath by an auxiliary researcher who did not participate in carrying out the intervention. To measure TT, the auxiliary researcher performed the traction of patients' right ear back and up for direct visualization of the ear canal; then placed the tip of a digital ear thermometer, covered with disposable plastic, in the ear canal to prevent air from entering. To measure the axillary temperature, the researcher checked whether patients' right armpit was dry, abducted patients' arms and positioned a digital thermometer in the central region of the axillary cavity. After the thermometer was positioned, the researcher performed adduction of the arm in order to keep the axillary cavity closed, flexed patients' arm over their chest and waited for the audible signal indicating the end of measurement. The value in degrees Celsius $\left({ }^{\circ} \mathrm{C}\right)$ shown on the digital screen of each thermometer was recorded on the data collection instrument.

In addition to the primary outcomes, data from patients' records were registered, characterization of participant data: age (years), sex (female/male), ethnicity (white, black, mixed race, other), cause of hospitalization (International Classification of Diseases - ICD-10 titles) and severity of patients (Simplified Acute Physiology Score III - SAPS III). Variables related to ICUs were also measured, such as the mean of ambient temperature (degrees Celsius) and humidity (percentage), in addition to the bath water temperature (degrees Celsius). To register these variables, a digital thermo-hygrometer (Incoterm 7663). It is worth mentioning that ICUs have a central air conditioning unit, responsible for maintaining the air-conditioned environment. The researchers did not interfere with the control of air conditioning temperatures, they only recorded the values found in each bath.

\section{Analysis of results, and statistics}

The data were entered, by two independent researchers, in the Microsoft Office Excel program, version 2013. To perform descriptive and inferential analysis, the program R-Bio, version 140 was used $^{(19)}$. The Shapiro-Wilk test was applied to data normality. In cases where the variables had a parametric distribution, Student's t-test for paired samples was used. For variables that presented non-parametric distribution, the Wilcoxon test was used. $\mathrm{P} \leq 0.05$ was considered significant.

\section{RESULTS}

At the end, the sample consisted of 50 patients, who received the traditional and dry bed bath (Figure 1). 


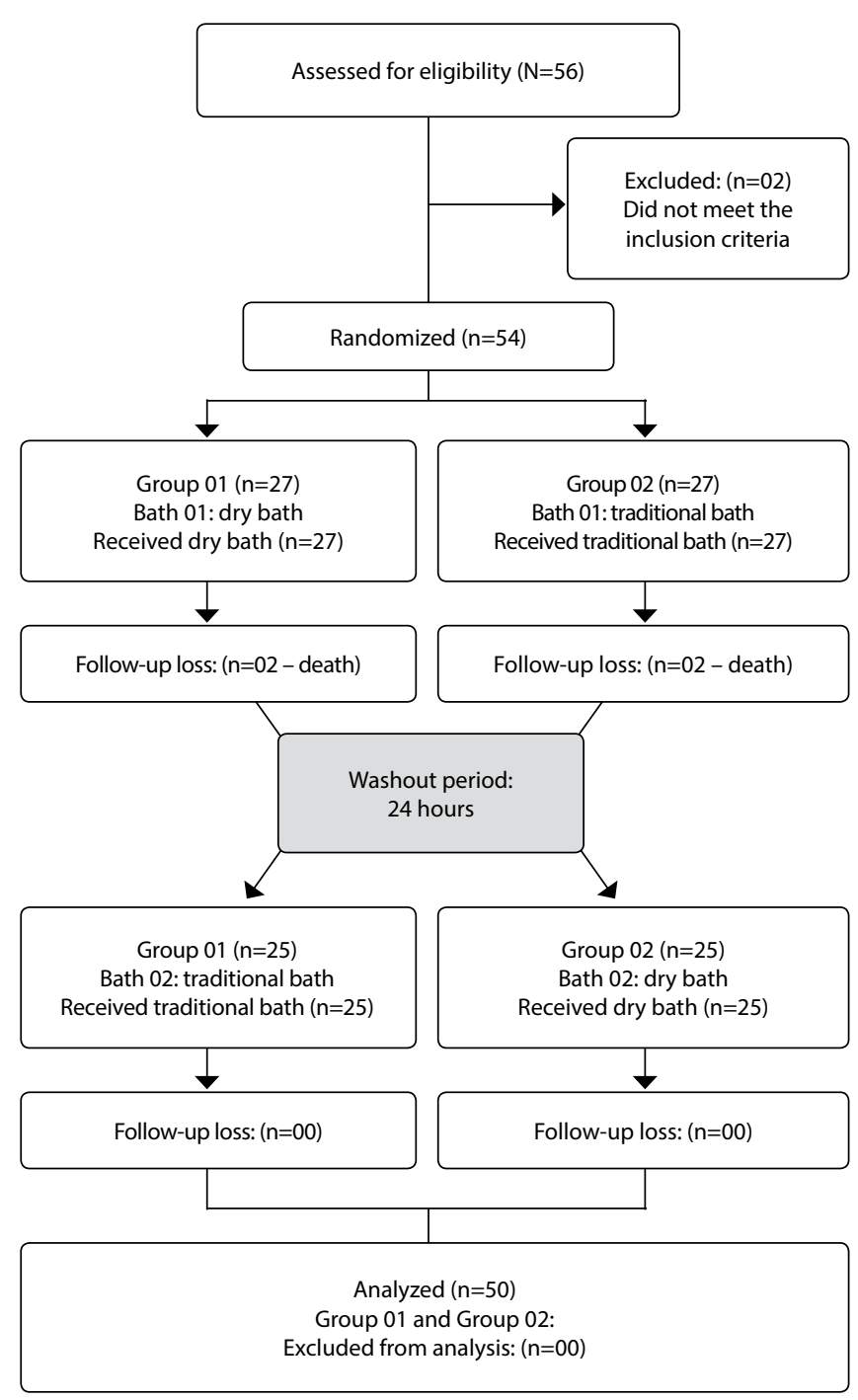

Source: Adapted from the CONSORT 2010 model: extension to randomized crossover trials(16). Figure 1 - Flowchart of sample tracking $(n=50)$, Viçosa, Minas Gerais, Brazil, 2019

Table 1 - Characterization of critical patients submitted to traditional and dry bed bathing, Viçosa, Minas Gerais, Brazil, 2019, $(n=50)$

\begin{tabular}{lc}
\hline Variables & Patients $(\mathbf{n}=\mathbf{5 0})$ \\
\hline Age/years & $68.64( \pm 18.99)^{*}$ \\
Sex & \\
$\quad$ Male & $28(56.00)^{* * *}$ \\
$\quad$ Female & $22(44.00)^{* *}$ \\
Causes of hospitalization according to the & \\
International Classification of Diseases (ICD-10) & $16(32.00)^{* * *}$ \\
$\quad$ Circulatory system diseases & $12(24.00)^{* *}$ \\
Respiratory system diseases & $07(14.00)^{* * *}$ \\
Digestive system diseases & $05(10.00)^{* * *}$ \\
Genitourinary system diseases & $05(10.00)^{* * *}$ \\
Musculoskeletal system diseases & $03(6.00)^{* * *}$ \\
Nervous system diseases & $01(2.00)^{* * *}$ \\
Some infectious diseases & $01(2.00)^{* * *}$ \\
External causes of morbidity and mortality & \\
Simplified Acute Physiology Score III (SAPS III) & \\
Score obtained by patients on the severity score & $54.56( \pm 15.99)^{*}$ \\
(points) & $28.91( \pm 23.65)^{*}$ \\
Mortality estimate &
\end{tabular}

The age of patients admitted to ICUs ranged from 24 to 100 years, with a mean of 68.64 years ( \pm 18.99 years). Most patients were male ( $28-56.00 \%)$, and the main causes of hospitalization were circulatory system-related diseases (16 - 32.00\%). Regarding the severity of patients' clinical picture measured by SAPS III, it was found that the mean score was 54.56 points (Table 1).

To assess changes in body temperature (tympanic and axillary), measurements were taken at the beginning and at the end of each of the two types of bed bath. The groups were considered comparable, as TT medians $\left(\mathrm{CG}=36.80^{\circ} \mathrm{C} ; \mathrm{EG}=36.80^{\circ} \mathrm{C}\right)$ and $\mathrm{AT}$ means $\left(C G=36.34^{\circ} \mathrm{C} ; \mathrm{EG}=36.09^{\circ} \mathrm{C}\right)$, obtained in the first measurement, were not considered statistically different by analysis of Wilcoxon test and Student's t-test for paired samples $(p=0.525$ and $\mathrm{p}=0.054$, respectively).

Concerning TT, no statistically significant changes were identified in either type of bath. In contrast, AT values, at the end of bathing, were lower than the initial values, both in traditional $(p=0.001)$ and in dry bathing $(p=0.001)$, as described in Table 2.

Table 2 - Comparison of the effect of traditional and dry bed bathing on tympanic and axillary body temperature of critically ill patients, recorded in degrees Celsius $\left({ }^{\circ} \mathrm{C}\right)$, Viçosa, Minas Gerais, Brazil, 2019, $(n=50)$

\begin{tabular}{lcccc}
\hline $\begin{array}{l}\text { Body } \\
\text { Temperature }\left({ }^{\circ} \mathrm{C}\right)\end{array}$ & Group & $\begin{array}{c}\text { Begining } \\
\text { of bath }\end{array}$ & End of bath & $\boldsymbol{p}$ value \\
\hline Tympanic $^{*}$ & $\mathrm{CG}^{* *}$ & $36.80( \pm 0.95)$ & $36.95( \pm 1.02)$ & $0.707^{\dagger}$ \\
& $\mathrm{EG}^{\ddagger}$ & $36.80( \pm 1.02)$ & $36.90( \pm 0.95)$ & $0.101^{\dagger}$ \\
Axillary & $\mathrm{CG}$ & $36.34( \pm 1.00)$ & $36.12( \pm 0.90)$ & $0.001^{\prime \prime}$ \\
& $\mathrm{EG}$ & $36.09( \pm 0.91)$ & $35.92( \pm 0.90)$ & $0.001^{\prime \prime}$ \\
\hline
\end{tabular}

Note: "Median (Interquartile range); ${ }^{* *} \mathrm{CG}$ - Control Group; ${ }^{\dagger}$ Wilcoxon test; ${ }^{*} E G$ - Experimental Group; ${ }^{5}$ Mean (Standard Deviation); "Paired Student's t-test; "Statistically significant $(p \leq 0.05)$.

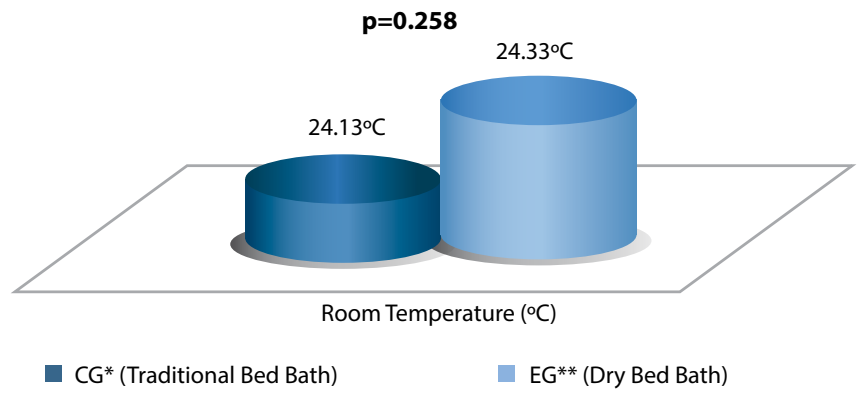

Note: CG - Control Group; EG - Experimental Group.

Figure 2 - Comparison of room temperature means of Intensive Care Units during traditional and dry bed bathing recorded in degrees Celsius $\left({ }^{\circ} \mathrm{C}\right)$, Viçosa, Minas Gerais, Brazil, 2019, $(n=50)$

When assessing the ICU environment's temperature during the two types of bath, it was found that the mean during the traditional bath $\left(24.13^{\circ} \mathrm{C} \pm 0.92\right)$ did not differ, statistically, from the mean during the dry bath $\left(24.33^{\circ} \mathrm{C} \pm 0.99\right)$, excluding its potential confounding effect (Figure 2).

With regard to the water temperature for traditional bed bathing, it was verified, by Student's t-test for paired samples, that there was no statistically significant difference $(p=0.389)$ between the means measured at the beginning $\left(45.30^{\circ} \mathrm{C}- \pm 4.85\right)$ and at the end of the procedure $\left(40.39^{\circ} \mathrm{C}- \pm 4.70\right)$. 


\section{DISCUSSION}

As for the profile of participants, it was found that the findings converged with data from other studies, in which there was a predominance of elderly critical patients, male and hospitalized due to circulatory system diseases ${ }^{(20-21)}$. Regarding patients'severity profile, it was found that the mean in the SAPS III score was 54.56 points, considered lower than that recorded in the literature, possibly associated with the absence of an intermediate care ICU in the studied hospital ${ }^{(22)}$. Nursing intervention to maintain body hygiene carried out in the bed, regardless of using water or pre-moistened wipes, did not cause significant changes in TT, but caused a significant reduction in AT values. This variation found only in AT may be related to its lower accuracy compared to the temperature measured by ear thermometers ${ }^{(1)}$. Furthermore, during the bed bath, the axillary region comes into direct contact both with water, in the traditional bath, and with the wet compress, in the dry bath. This contact can change the local temperature and, consequently, reflect in the greater variation of the measured temperature. Such fact does not occur with measurement in the auditory canal, whose cleaning is performed only externally.

Elders prevailing is a condition that arouses the attention of the nursing staff to monitor and maintain the thermal balance of these patients, because extreme age causes them to be classified as a risk population for different nursing diagnoses (ND) associated with thermoregulation ${ }^{(6)}$. According to the NANDA-I taxonomy, this ND population can be attributed to illustrate real problems such as Hypothermia (00006) and Ineffective Thermoregulation (00008), in addition to those that represent potential problems, such as Risk for Hypothermia (00253) and Risk for Ineffective Thermoregulation $(00274)^{(6)}$. With advancing age, patients have a reduced ability to maintain thermal homeostasis, particularly when exposed to low ambient temperatures. This fact is associated with the presence of metabolic and structural changes in the skin, common to the aging process $^{(23)}$. These conditions reinforce the importance of adequate planning and safety in the execution of nursing interventions that can increase this exposure, such as bed bathing.

When assessing the changes in body temperature of critically ill patients submitted to the traditional bed bath and dry bed bath, there was greater stability of $\mathrm{TT}$ compared to AT, since there was no significant difference in median values of TT before and after the baths. In turn, patients had lower means of AT at the end of each bath when compared to the values initially measured. Different researchers argue that body temperature measured non-invasively, using axillary thermometers, is not the most reliable method for the control of critical patients $s^{(7)}$. However, as seen in the scenario of this study, as it is an accessible, practical and low cost method, AT remains used in different ICUs as a reference parameter for therapeutic approaches ${ }^{(24)}$.

The presence of central body temperature below $36^{\circ} \mathrm{C}$ is defined as hypothermia and is associated with higher patient mortality (OR $2.093,95 \% \mathrm{Cl} 1.704-2.570)$ when compared to normothermic ones ${ }^{(25)}$. In general, the central body temperature of individuals is higher than the values obtained from non-invasive thermometers, such as ear and axillary. A recent systematic review defined TT values between 35.76 and $37.52^{\circ} \mathrm{C}$ and AT between $35.01^{\circ} \mathrm{C}$ and $36.93^{\circ} \mathrm{C}$ as the normal range ${ }^{(26)}$. In view of these results, it cannot be said that the bed bath is capable of causing hypothermia in critically ill patients, since the values measured at different times and between different baths were considered within the normal range. However, it can be inferred that this important body hygiene intervention is capable of causing significant changes in the AT of critical patients who deserve attention from the nursing staff, especially as this is the measurement method that is even more used in ICUs.

For patients admitted to ICUs, central body temperature monitoring using urinary, nasopharyngeal or esophageal thermometers is recommended. Among non-invasive temperatures, the incorporation of TT is encouraged. as a method of choice for non-invasive measurement due to the greater reliability of data ${ }^{(1)}$. In cases where its implementation is not possible, the interpretation of AT values should be performed with caution due to the possibility of being influenced by external factors, such as the ambient temperature ${ }^{(9,27)}$. In this study, the room temperature mean was assessed during each bath, verifying that there was no difference between the means found, being $24.13^{\circ} \mathrm{C}( \pm 0.92)$ in traditional bathing and $24.33^{\circ} \mathrm{C}$ $( \pm 0.99)$ in dry bathing. Based on these results, one can exclude the possible confounding effect of this variable.

In the same way, we sought to exclude the confounding effect of the water temperature used in the traditional bed bath by comparing the values of this variable at different times of measurement. The means of water temperature found at the beginning $\left(45.30^{\circ} \mathrm{C}\right.$ $\pm 4.85)$ and at the end of the bath $\left(40.39^{\circ} \mathrm{C} ; \pm 4.70\right)$ were not statistically different. In the two measurements, the values were higher than $40.00^{\circ} \mathrm{C}$, being considered for critical heart disease patients as an adequate temperature to avoid the occurrence of changes in heart rate, arterial oxygen saturation, and $\mathrm{AT}^{(8)}$. In turn, contact with cold water can trigger hemodynamic imbalance reactions due to the increased speed of heat losses, making it an important variable to be considered by the nursing staff during bathing ${ }^{(9)}$.

In this study, the absence of water for dry bed bathing did not present advantages for patients'thermal balance, since reduction in AT was present in patients submitted to both types of bed bathing. In contrast, critical patients in the postoperative period of cardiac surgery submitted to different types of bath, such as the traditional method, with hydrothermal control at $42.50^{\circ} \mathrm{C}$, and the dry method, with tissues heated in a microwave for 20 seconds, showed no changes in $\mathrm{AT}^{(28)}$. It is believed that this difference between the results may be associated with the characteristics of patients assessed, as well as constant bath water temperature maintenance and pre-moistened wipe heating. It should be noted that, in the present investigation, dry bath packaging was applied at room temperature to illustrate the reality of local ICUs, which do not have a specific microwave device for this purpose.

It is noteworthy that nursing interventions must be planned individually and based on priority criteria, as procedures considered simple by the nursing staff, such as the bed bath, can trigger significant reductions in critical patients' $\mathrm{AT}$, as verified in this investigation.

\section{Study limitations}

This study has a limitation of having been carried out in a single ICU that attends patients with different levels of complexity, and not just those of high complexity. The hospital does not have a semi-intensive care unit and therefore less severe patients are also 
admitted to ICUs. Therefore, the results described here should be interpreted with caution. Finally, it is noteworthy that although convenience sampling was used, the number of patients assessed was higher than that found in other clinical studies whose object was bed bathing.

\section{Contributions to nursing}

The results presented by this clinical study have direct implications for the practice of nursing, awakening in professionals the view of bed bath as a potential risk for reductions in AT in critically ill patients and the adoption of measures that can minimize this risk. Thus, when performing this intervention, the nursing staff must be attentive, not only to the technical rigor with the procedure, but also to the risks that patients are exposed to, in order to prevent its occurrence. Regardless of the method of bed bath employed, it is expected that professionals ensure a lower patient exposure during this intervention, as well as the monitoring of body, room and water temperatures. It raises the need for studies to assess the effect of bed bathing on invasive methods of measuring body temperature, as well as the effectiveness of preventive measures to reduce the peripheral temperature of critically ill patients undergoing different types of bed bath.

\section{CONCLUSIONS}

In this study, bed bathing, regardless of the method used for its execution, was able to cause changes in the thermal balance of critical patients. AT means, verified at the end of traditional and dry bed bathing, were considered lower than the values measured initially, however they remained within the normal range. Regarding TT, there were no significant changes with the baths.

These results reinforce the importance of the nursing staff care to carry out an effective body hygiene practice and with greater safety. To this end, it is necessary adequate performance of the technique itself and lower patient exposure during the procedure, monitoring and control of vital parameters, such as body temperature, during its performance.

\section{REFERENCES}

1. Asadian S, Khatony A, Moradi G, Abdi A, Rezaei M. Accuracy and precision of four common peripheral temperature measurement methods in intensive care patients. Med Devices (Auckl). 2016;9:301-8. https://doi.org/10.2147/MDER.S109904

2. Obermeyer Z, Samra JK, Mullainathan S. Individual differences in normal body temperature: longitudinal big data analysis of patient records. BMJ. 2017;359:j5468. https://doi.org/10.1136/bmj.j5468

3. Cutuli SL, Osawa EA, Glassford NJ, Marshall D, Eyeington, CT, Eastwood GM, et al. Body temperature measurement methods and targets in Australian and New Zealand intensive care units. Crit Care Resusc [Internet]. 2018[cited 2020 Jul 12];20:241-4. Available from: https://pubmed.ncbi.nlm.nih. gov/30153787/

4. Basak T, Aciksoz S, Tosun B, Akyuz A, Acikel C. Comparison of three different thermometers in evaluating the body temperature of healthy young adult individuals. Int J Nurs Pract. 2013;19(5):471-8. https://doi.org/10.1111 / ijn.12097

5. Poveda VB, Nascimento AS. Intraoperative body temperature control: esophageal thermometer versus infrared tympanic thermometer. Rev Esc Enferm USP. 2016;50(6):945-50. http://dx.doi.org/10.1590/S0080-623420160000700010

6. Herdman TH, Kamitsuru S. NANDA International nursing diagnoses: definitions and classification, 2018-2020. 11th ed. New York: Thieme Publishers. 2018. $512 \mathrm{p}$.

7. Carvalho RLR, Victoriano MA, Campos CC, Matos SS, Gouveia VR, Ercole FF. Identification of factors that alter axillary temperature reliability in relation to pulmonary artery catheter temperature. Rev Min Enferm. 2019;23:e-1267. https://doi.org/10.5935/1415-2762.20190115

8. Silva CJB, Silva MES, Reis FF, Miranda GCO, Santos L, Lima DVM. Bed bath for infarcted patients: crossover of the hydrothermal control $40^{\circ} \mathrm{C}$ versus 42.5 C. O Braz J Nurs [Internet]. 2016 [cited 2020 Jul 12];15(3):341-50. Available from: http://www.objnursing.uff.br/index.php/nursing/ article/view/4233

9. Oliveira AP, Lima DVM, Lacerda RA, Nascimento MAL. Correlations between ICU ambient temperature and blood oxygen saturation and body temperature of critically ill patients during bedbathing. Rev Ref [Internet]. 2009 [cited 2020 Jul 12];11:61-8. Available from: http:// www.index-f.com/referencia/2009pdf/11-6168.pdf

10. Mooler G, Magalhães AMM. Bed baths: nursing staff workload and patient safety. Texto Contexto Enferm. 2015;24(4):1044-52. https://doi. org/10.1590/0104-0707201500003110014

11. Medeiros ABA, Enders BC, Lira ALBC The Florence Nightingale's Environmental Theory: a critical analysis. Esc Anna Nery. 2015;19(3):518-24. https://doi.org/10.5935/1414-8145.20150069

12. Toledo LV, Santos BX, Salgado PO, Souza CC, Brinati LM, Ercole FF. Efeitos oxi-hemodinâmicos de diferentes tipos de banho no leito em pacientes críticos: revisão sistemática. In: Oliveira ACO. O conhecimento na competência da teoria e da prática em Enfermagem 3. Atena editora. 2019;3(1):62-76. https://doi.org/10.22533/at.ed.6951912036

13. Bastos SRB, Gonçalves FAF, Bueno BRM, Silva GS, Ribeiro KRA, Brasil VV. Bed-bath: The care-omitting behavior of the nursing team. Rev Pesqui: Cuid Fundam. 2019;11(3):627-33. https://doi.org/10.9789/2175-5361.2019

14. Skewes SM. Skin care rituals that do more harm than good. Am J Nurs. [Internet]. 1996 [cited Mar 05, 2020];96(10):33-5. Available from: https://insights.ovid.com/pubmed?pmid=8863646. 
15. Toledo LV, Salgado PO, Souza CC, Brinati LM, Januário CF, Ercole FF. Effects of dry and traditional bed bathing on respiratory parameters: a randomized pilot study. Rev Latino-Am Enfermagem. 2020;28(e3264):1-9. https://doi.org/10.1590/1518-8345.3668.3264

16. Dwan K, Li T, Altman DG, Elbourne D. CONSORT, 2010. statement: extension to randomized crossover trials. BMJ. 2019;366:14378. https:// doi.org/10.1136/bmj.14378

17. Paulela DC, Bocchi SC, Mondelli AL, Martin LC, Sobrinho AR. Effectiveness of bag bath on microbial load: clinical trial. Acta Paul Enferm. 2018;31(1):7-16. https://doi.org/10.1590/1982-0194201800003

18. Coluci MZO, Alexandre NMC, Milani D. Construction of measuring instruments in the health. Ciênc Saúde Colet[Internet]. 2015 [cited 2019 Mar 2];20(3):925-36. Available from: https://doi.org/10.1590/1413-81232015203.04332013

19. Bhering LL. Rbio: A Tool For Biometric And Statistical Analysis Using The R Platform. Crop Breeding and Applied Biotechnology. 2017;17:187190. https://doi.org/10.1590/1984-70332017v17n2s29

20. Park J, Jeon K, Chung CR, Yang JH, Cho YH, Cho J. et al. A nationwide analysis of intensive care unit admissions, 2009-2014 - The Korean ICU National Data (KIND) study. J Crit Care. 2018;44:24-30. https://doi.org/10.1016/j.jcrc.2017.09.017

21. Vieira AM, Parente EA, Oliveira LS, Queiroz AL, Bezerra ISAM, Rocha HAL. Characteristics of deaths of hospitalized patients in Intensive Care Unit of a tertiary hospital. J Health Biol Sci. 2019;7(1):26-31. https://doi.org/10.12662/2317-3076jhbs.v6i4.1999.p26-31.2019

22. Toker MK. SAPS III or APACHE IV: Which score to choose for acute trauma patients in intensive care unit? Ulus Travma Acil Cerrahi Derg. 2019;25:247-252. https://doi.org/10.5505/tjtes.2018.22866

23. Blatteis CM. Age-dependent changes in temperature regulation: a mini review. Gerontology. 2012;58(4):289-295. https://doi. org/10.1159/000333148

24. Corrêa F, Silveira LM, Lopes NAP, Ruffino-Netto A, Stabile AM. Perfil de termorregulação e desfecho clínico em pacientes críticos com sepse. Av Enferm. 2019;37(3):293-302. https://doi.org/10.15446/av.enferm.v37n3.77009

25. Kiekkas P, Fligou F, Igoumenidis M, Stefanopoulos N, Konstantinou E, Karamouzos V, et al. Inadvertent hypothermia and mortality in critically ill adults: Systematic review and meta-analysis. Aust Crit Care. 2018; 31(1):12-22. https://doi.org/10.1016/j.aucc.2017.01.008

26. Geneva II, Cuzzo B, Fazili T, Javaid W. Normal body temperature: a systematic review. Open Forum Infect Dis. 2019;6(4):ofz032. https://doi. org/10.1093/ofid /ofz032

27. Erenberk U, Torun E, Ozkaya E, Uzuner S, Demir AD, Dundaroz R. Skin temperature measurement using an infrared thermometer on patients who have been exposed to cold. Pediatr Int. 2013;55:767-770. https://doi.org/10.1111/ped.12188

28. Lobo ABAP, Santos SRM, Mesquita Jr LCM, Fernandes RM, Santos MP, Reis FF, et al. Oxyhemodynamic effectiveness of three types of bed baths for patients with severe heart disease: crossover. Res Soc Developm. 2020;9(8):e954986249. https://doi.org/10.33448/rsd-v9i8.6249 